\title{
17. THE VARIATION OF THE HYDRAULIC CONDUCTIVITY STRUCTURE OF AN OVERPRESSURED THRUST ZONE WITH EFFECTIVE STRESS ${ }^{1}$
}

\author{
Kevin M. Brown ${ }^{2}$
}

\begin{abstract}
Ocean drilling program (ODP) Site 892 provides a unique opportunity to study the hydraulic and physical properties of an out-of-sequence thrust zone within the Cascadia accretionary wedge off the Oregon shore. The hydraulic conductivity $(K)$ profile at Site 892 shows a clear minimum $\left(K=\sim 2 \times 10^{-9} \mathrm{cms}^{-1}\right)$ centered at $\sim 70 \mathrm{mbsf}$, close to the hanging wall contact of the major hydrogeologically active thrust zone. This minimum appears to relate to enhanced cementation at this level. The hydraulic conductivity increases by two to three orders of magnitude downwards into the fault zone $\left(K=\sim 8 \times 10^{-7}\right.$ to $\left.8 \times 10^{-6} \mathrm{cms}^{-1}\right)$ suggesting that migrating fluids could be trapped in the fault zone by the strong vertical hydraulic conductivity contrasts. Samples taken from the hanging wall and fault zone have distinctly different volumetric and hydraulic conductivity responses to varying effective stress. The hanging wall samples have low hydraulic conductivities that do not change significantly with variations in effective stress. In contrast, the volumetrically stiffer fault zone samples show large changes in $K$ (i.e., several orders of magnitude) with varying effective stress. This type of strongly coupled stress and $K$ behavior will create a highly non-linear hydrogeologic system in the fault zone. Based on maximum past consolidation stress estimates, the fault zone appears to be strongly overpressured. The overpressures increase downwards, with $\lambda *$ increasing from $\sim 0.0-0.4$ at the upper hanging wall contact at $\sim 70 \mathrm{mbsf}$ to approach 0.8 in the mélange zone associated with the out-of-sequence thrust. This degree of overpressuring is required to maintain the fault zone's high hydraulic conductivities and hydrogeologic system; active fluid flow would be rapidly shut down if the fluid pressure dropped towards hydrostatic values.
\end{abstract}

\section{INTRODUCTION}

Ocean Drilling Program (ODP) Leg 146 Site 892 was drilled to a depth of $\sim 163$ meters below seafloor (mbsf), just west of the crest of the second ridge within the accretionary wedge off the Oregon shore (Fig. 1). The overall drilling objectives at this site were the investigation of the physical properties associated with both the bottom-simulating reflector (BSR) situated at $\sim 73 \mathrm{mbsf}$ and a major, hydrogeologically active, landward-dipping thrust fault (Shipboard Scientific Party, 1994; Carson and Westbrook, this volume; Moore, et al., in press.). Based on seismic reflection sections, this thrust fault lies at $\sim 107-113$ mbsf. The most intense deformation, however, was observed in the cores over a range of depths between $\sim 100$ and 150 mbsf. The primary objectives of this laboratory study are the following: (1) the provision of additional constraints on the state of consolidation and degree of overpressuring of the sediments at this site; and (2) the determination of how effective stress and fluid pressure fluctuations control the nature of the volume and hydraulic property changes within the variably fractured muds that comprise the fault zone.

The sediments at this site are lithologically relative 'uniform, consisting predominantly of terrigenous and hemipelagic c c..yey silts and silty clays. Above $\sim 68 \mathrm{mbsf}$, however, the clay-rich sediments also contain local thin terrigenous and glauconitic sand layers. The $\sim 68 \mathrm{mbsf}$ boundary is associated with a thin cemented sand layer and a sharp downward decrease $(\sim 10 \%)$ in water content (Fig. 2; Shipboard Scientific Party, 1994). Below this boundary there are fewer sand layers and the degree of stratal disruption increases. The deeper regions of Site 892 are characterized by pervasive stratal disruption

'Carson, B., Westbrook, G.K., Musgrave, R.J., and Suess, E. (Eds.), 1995. Proc. ODP, Sci. Results, 146 (Pt. 1): College Station, TX (Ocean Drilling Program).

${ }^{2}$ Scripps Institution of Oceanography, University of California at San Diego, La Jolla, CA 92093-0220, U.S.A. significantly enough to be characterized as a tectonic mélange between $\sim 100-150$ mbsf (Shipboard Scientific Party, 1994). Microscopic analysis of specimens from the shear zones in the fractured muds show polished and striated surfaces that surround relatively indurated phacoids (Clennell and Maltman, this volume). The physical properties (i.e., water content) at Site 892 show abrupt discordances at 17, 68, 116, and 144 mbsf (Fig. 2; Shipboard Scientific Party, 1994). The discordance at $17 \mathrm{mbsf}$ appears to relate to the presence of abundant gas hydrate in the sediments above. The $\sim 68$ mbsf physical property boundary and associated cementation is related either to diagenesis at the base of the hydrate zone and BSR level or precipitation of mineral phases around a fluid conduit found at this level (Shipboard Scientific Party, 1994). In contrast, the excursions to lower water contents at $\sim 116$, and $\sim 144$ clearly relate to zones of stratal disruption that are identifiable in the cores. These deformed and hydrogeologically active regions may all represent strands of the same major thrust zone identified in the seismic sections. It is possible that some are also features from earlier deformation phases. The geophysical logs (Shipboard Scientific Party, 1994) indicate anomalous zones of high density, velocity, and resistivity between 61 and $68 \mathrm{mbsf}$ and also between 83 and 93 mbsf. These dense zones are also spatially associated with temperature anomalies. The anomalies are consistent with the current lateral input of warm water along relatively narrow conduits situated $\sim 67, \sim 87 \mathrm{mbsf}$, and $\sim 100 \mathrm{mbsf}$ (see Davis et al., this volume; Shipboard Scientific Party, 1994). The presence of higher hydrocarbon gases (ethane through hexane) also suggests that thermogenic gases have been laterally input into the section along conduits situated at $\sim 67 \mathrm{mbsf} \pm 10 \mathrm{~m}, \sim 107 \mathrm{mbsf} \pm 10 \mathrm{~m}$, and $\sim 125 \mathrm{mbsf}$ $\pm 10 \mathrm{~m}$ (Fig. 2; Shipboard Scientific Party, 1994). Under conditions of normal consolidation, the clay-rich lithologies that predominate at this site should develop relatively low matrix hydraulic conductivities and are not prime candidates for substantial focused flow. What then allows fluid flow to be focused along the various levels in the thrust zone at this site? 


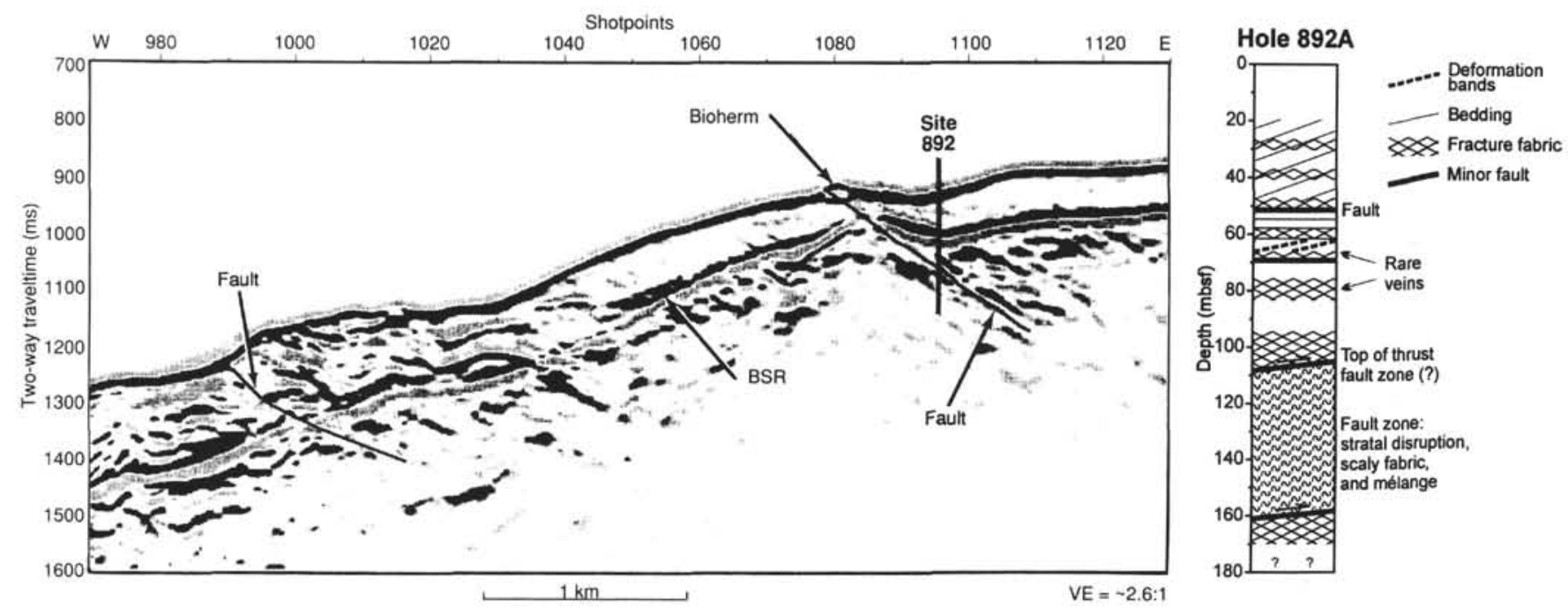

Figure 1. Seismic reflection section and structural log from Site 892 (Shipboard Scientific Party, 1994). The surface trace of the thrust fault is the site of active fluid venting and bioherm development (Moore et al., in press.).

\section{EXPERIMENTAL APPARATUS AND PROCEDURE}

The basic features of the constant flow-rate permeameter used to determine the hydraulic conductivities of core samples collected from Site 892 are shown in Figure 3. Before measuring them, the samples were kept moist in sealed containers and stored at $4^{\circ} \mathrm{C}$. The ends of the cylindrical hydraulic conductivity samples were cut to the required length and the sample dimensions were determined before placement in the confining chamber (average sample dimensions were $\sim 2.54 \mathrm{~cm}$ in diameter and 0.7 to $1.5 \mathrm{~cm}$ long). The samples were placed between titanium (selected for its corrosion resistance) platens, and an impermeable flexible polyurethane jacket was cast around the whole sample assembly to isolate the sample from the fluid producing the confining pressure. The system design allows fluids to be pumped along the axis of the sample via ports and inert porous plastic plates at the top and base of the sample assembly (Fig. 3). All tubing was fabricated of high pressure PEEK plastic to alleviate corrosion problems in the presence of the artificial saline pore fluid.

The sample assembly was then placed in the confining chamber and the external system pressurized (Fig. 3). Care was taken not to exert an excessive effective stress on the sample during the setup period prior to the incremental consolidation tests. To force any remaining air into solution, previously de-aired artificial pore fluid was introduced into the internal system and sample; the system was subsequently back pressured to $300 \mathrm{kPa}$. The major cation composition of the artificial pore fluid was made to correspond to the in situ pore fluid values at a particular sample depth. The composition was determined from pore fluids extracted from the cores aboard ship (Shipboard Scientific Party, 1994). Particular attention was paid to the $\mathrm{Na}$, $\mathrm{Mg}, \mathrm{Ca}$, and $\mathrm{K}$ concentrations and the $\mathrm{pH}$; the other cations occurred in very small quantities and were ignored for the purposes of these tests.

Hydraulic conductivity determinations were attempted at more than one flow rate to verify if a constant flow was achieved through the samples. The effective confining stress was also changed incrementally to assess how it affected the volume and hydraulic conductivity of the sample. A constant flow rate was maintained during the hydraulic conductivity tests with a variable speed syringe pump, manufactured by Harvard Apparatus. Flow rates are considered to be accurate to $\pm 0.5 \%$ at the middle range, and $\pm 2 \%$ at the lowest range.

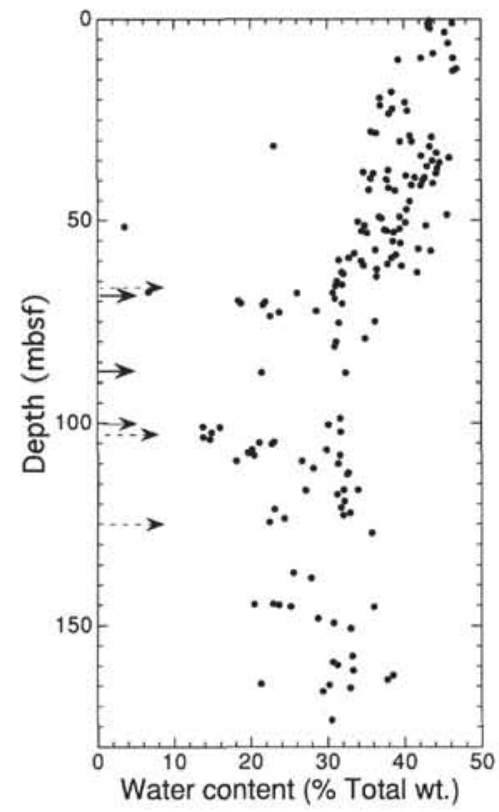

Figure 2. Discrete water content measurements from shipboard composite data (Shipboard Scientific Party, 1994). Position of the temperature anomalies are marked with solid arrows, thermogenic hydrocarbon anomalies are marked with dashed arrows. Accuracy of the position of the thermal anomalies $\pm \sim 5 \mathrm{~m}$. Note the association of anomalously low water content regions with the thermal and geochemical anomalies (particularly at $\sim 70 \mathrm{mbsf}$ and $\sim 100$ mbsf where a higher density of data exists).

The flow pump technique has several advantages over the standard constant head and falling head methods of hydraulic conductivity measurement; the most important being the ease with which very low flow rates (and hence low hydraulic gradients) can be reliably maintained (Olsen et al., 1988; Olsen et al., 1985; Olsen and Daniel, 1981; Pane et al., 1983). In all tests, the flow rate was chosen so that the excess pore pressure generated was $<10 \%-15 \%$ of the average effec- 


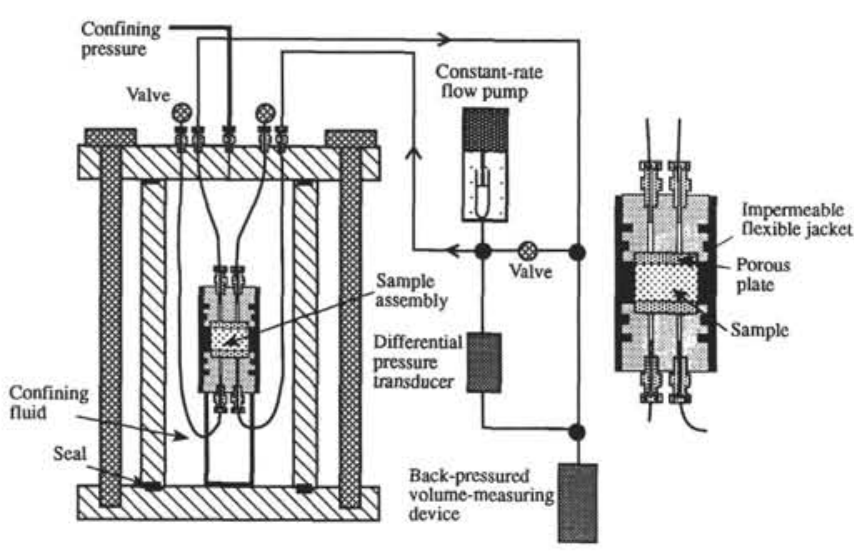

Figure 3. Schematic diagram of the constant rate flow-pump permeability apparatus used in this study.

tive stress imposed on the sample. This was done in order to minimize sample disturbance caused by seepage-induced consolidation (Pane et al., 1983; Olsen et al., 1985).

The outflow side of the sample was kept at a constant fluid backpressure (Fig. 3) and was, in the later series of determinations, connected to a volume-measuring device accurate to $\pm 0.01 \mathrm{~cm}^{3}$. The void ratio $(e)$ vs. effective stress relationships (where $e=V / V$, and $V_{v}$ and $V_{s}$ are, respectively, the volume of the voids and the solids) were determined using the volume changes measured at each incremental change in effective stress in conjunction with the sample's initial/final void ratio obtained by oven-drying sub-samples at the beginning and end of each test run.

Characteristically, the differential pressure across the sample during a flow-pump test increases from zero to a maximum constant value corresponding to a steady-state pressure gradient. The hydraulic conductivity, $K$, was then calculated using the sample's dimensions, Darcy's law, and the steady-state head difference (Freeze and Cherry, 1979) across the sample:

$$
K=\frac{q}{A}\left(\frac{d h}{d l}\right)^{-1}
$$

where $q$ is the volumetric flow rate $\left(\mathrm{cm}^{3} / \mathrm{s}\right), A$ is the cross sectional area of the sample (in $\mathrm{cm}^{2}$ ) normal to the direction of flow, and $d h / d l$ is the steady state head gradient across the sample ( $l$ is the sample length [in $\mathrm{cm}], h$ is head [in $\mathrm{cm}]$ ).

\section{EXPERIMENTAL OBJECTIVES AND METHODS}

The primary aim of these experimental determinations was to investigate the following properties: (1) the hydraulic conductivity structure of the fault zone and hanging wall sequences; (2) the variation in the $e$ and $K$ of the samples with effective confining stress; and (3) the maximum effective consolidation stress and degree of overpressuring to which the samples had been subjected in the fault zone.

A problem with this type of investigation is that the stress state is typically not very well known in accretionary prisms. At Site 892 , the sediments are visibly deformed (Clennell and Maltman, this volume) and the various strands of the major thrust fault intersected at this site may have been recently active. Thrust faults form under conditions where the principal compressive stress is subhorizontal. However, inferences drawn from the results of the packer test indicate that the principal compressive stress may now be oriented at a relatively steep angle (Screaton et al., this volume). It is, thus, unclear as to whether the principal stress has been relatively at a steep or at a low angle through much of the recent period of evolution in the sediments' physical properties. The isotropic effective stress $\left(\sigma_{i}{ }^{\prime}\right)$ conditions that the samples were subject to in this laboratory study are essentially intermediate between these two possible end member stress states (i.e., low- and high-angle orientation of the principal stress). A second problematic aspect is whether the moderate degree of overpressuring that has been identified by the packer tests at this site (also see Screaton et al., this volume) was at similar levels in the past. Data from Screaton et al., (this volume) indicate that the in situ fluid pressure was $\sim 0.25$ to $\sim 0.3 \mathrm{Mpa}$ greater than the hydrostatic pressure in the screened region below the packer at the time of the test. The packer was set at $93.6 \mathrm{mbsf}$ and essentially these overpressures could exist anywhere in the screened interval between 93.6 to $116 \mathrm{mbsf}$.

Because of these unknowns, the hydraulic conductivities of the samples in this study were determined during the incremental increases in isotropic effective confining stress starting at low stress levels. Initially, only hydraulic conductivity vs. effective stress data were collected as part of this study. Subsequently, construction of volumetric devices also allowed changes in sample volume to be monitored. These latter studies still in progress.

Typically, during reloading, the sample initially responds elastically up to the level of the maximum previous effective stress experienced during its burial history (termed the maximum preconsolidation stress). Subsequently, plastic deformation associated with higher effective stresses leads to a larger volumetric response. When $e$ is plotted against the $\log$ of the effective stress, two approximately linear portions of the loading curve can be seen, with a break in slope between the shallower elastic portion of the curve and the steeper plastic portion of the curve. In one dimensional consolidation tests, the maximum preconsolidation stress, $P_{c}^{\prime}$ (Casagrande, 1936; Lambe and Whitman, 1979), is obtained from the location of the break in slope between the elastic and plastic portions of the consolidation curves (with $e$ being plotted against the log of effective vertical stress or $\log \sigma_{v}{ }^{\prime}$ ). The effective overburden stress under hydrostatic conditions, $P_{o}^{\prime}$, is estimated by integrating the shipboard discrete bulk density data from the surface to the sample depth to obtain the lithostatic overburden pressure $P_{o}$ (Shipboard Scientific Party, 1994) and then subsequently subtracting the hydrostatic pressure $\left(P_{o}^{\prime}=P_{o}-P_{h}\right.$, where hydrostatic pressure, $P_{h}$ is determined assuming the pore fluids have the density of seawater). The sediments are considered to be normally consolidated if the current effective overburden stress is the greatest ever imposed, i.e., if $P_{o}{ }^{\prime}$ equals $P_{c}^{\prime}$. If $P_{c}^{\prime}$ is less than $P_{o}^{\prime}$, the sample is underconsolidated and over pressured. Conversely, if $P_{c}{ }^{\prime}$ is greater than $P_{o}^{\prime}$, the sample is overconsolidated (Lambe and Whitman, 1979). In a similar fashion, the volumetric behavior of the samples being exposed to an isotropic stress, $\sigma_{i}^{\prime}$, in this study can also be used to estimate the maximum preconsolidation stress. The values of the maximum preconsolidation stress obtained from the isotropic stress path determinations conducted during this study are denoted by $P_{i}^{\prime}$ to distinguished them from $P_{c}{ }^{\prime}$ (the latter is the more conventional method of evaluation based on one-dimensional consolidation studies). The variation in $K$ with effective stress can also be used to give a separate indication of the maximum preconsolidation stress. On examination of the $\log \sigma_{i}{ }^{\prime}$ vs. (Fig. 4) the differences in evolution in $K$ along the elastic and plastic portions of the stress paths can also be separated because of the linear relationships between $e v \mathrm{~s} . \log \sigma_{i}{ }^{\prime}$ and $e$ vs. $\log K$ (Lambe and Whitman, 1979). The slope of the curve in the elastic portion of the stress path is relatively low, corresponding to a stiffer volumetric response of the sample. As the sample begins to consolidate plastically, the slope of the $\log \sigma_{i}{ }^{\prime}$ vs. $\log K$ curve steepens. The position of this break in slope can be used to give an indication of the sample's maximum previous consolidation stress and has been denoted separately as $P_{i} *^{\prime}$. An estimate of the excess fluid pressure, $P_{\text {flexcess) }}$ (the component above hydrostatic) can also be obtained by subtracting the $P_{i}^{\prime}$ and $P_{i} *^{\prime}$ 
A
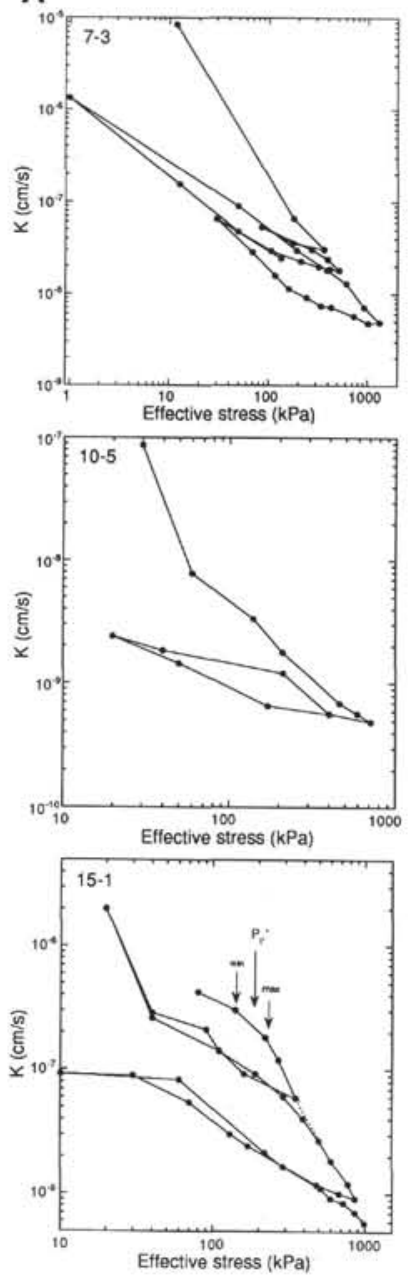

Figure 4. Plots of $\log K$ vs. $\log \sigma_{i}^{\prime}$ data for various samples (sample numbers marked on figure, see Table 1 for ODP sample codes). Arrow denotes estimated value for $P_{i} *^{\prime}$.

estimates from $P_{o}$ ' following an adaptation of the effective stress law, $P_{\text {flexcess }}=P_{o}^{\prime}-\left(P_{i}^{\prime}\right.$ or $\left.P_{i} *^{\prime}\right)$.

Note that, given the probable complexity of the strain history of the samples obtained at this site, any $P_{c}{ }^{\prime}, P_{i} *^{\prime}$, and $P_{i}^{\prime}$ values are considered to be only an approximate indication of the effective preconsolidation stress. Despite this, it is still possible to evaluate whether the samples are grossly over- or underconsolidated with respect to their current expected stress state under hydrostatic conditions. An additional evaluation of the degree of sample disturbance that has occurred in these specimens can also be made. For example, a sharp reload to virgin curve transition (i.e., sharp break in slope between the elastic and plastic portions of the consolidation curve) of the $e$ vs. $\log$ $\sigma_{i}{ }^{\prime}$ curve would be indicative of minimum disturbance. In this study, the samples exhibit variable degrees of sample disturbance and evidence for fracture closure episodes.

\section{EXPERIMENTAL RESULTS}

\section{Estimation of the Maximum Past Consolidation Stress}

The experimental results have been separated into two broad categories. In Figure 4 the $\log K$ vs. $\log \sigma_{i}{ }^{\prime}$ relationships are plotted for the initial series of tests on these samples. In Figures 5 through 8 the complete set of volumetric and hydraulic conductivity data are presented for the most recently run samples. The depths and other measured parameters for these samples are given in Table 1.

From Figure 4 it can be seen that samples 8-4 and 15-1 (and to a lesser extent 11-1) exhibit moderately undisturbed initial reload characteristics and can be used to evaluate $P_{i} *^{\prime}$ (see Table 1 for sample depths and full ODP sample numbers). In contrast, samples 7-3 and 10-5 show little definition between the elastic and plastic portions of the stress path and cannot be used to estimate $P_{i} *^{\prime}$. A reasonably conservative estimate of the potential maximum range in $P_{i} *^{\prime}$ is determined by examining the shape of the curves and determining where the curve departs from the linear trends corresponding to the plastic (maximum values) and elastic (minimum values) portions of the stress path (see Fig. 4 for example sample 15-1). Note that because sample disturbance should result in an underestimation of $P_{i} *^{\prime}$, it is likely that the actual values are closer to the $P_{i} *^{\prime}$ maximum values than to the minimum values.

A full set of volumetric and hydraulic conductivity data is now available for samples 5-1, 7-4, 9-1, 16-4, 10-8, 18-1, and 20-2 (see Table 1; Figs. 5-8). Where possible, the maximum past consolidation stress $P_{i}^{\prime}$ was obtained from the $e$ vs. $\log \sigma_{i}^{\prime}$ curves using Casagrande's (1936) technique (see also Lambe and Whitman, 1979). The maximum range estimates for the values of $P_{i}^{\prime}$ are obtained in the same way as those for $P_{i} *^{\prime}$ by using the points of definite departure from the linear trends corresponding to the plastic and elastic portions of the $e$ vs. $\log \sigma_{i}^{\prime}$ curves (see for example Fig. 8A). The variety of available data allows separate estimations of $P_{i}{ }^{\prime}$ and $P_{i} *$ for these samples (see Table 1 and Fig. 9A). The two methods of estimating the maximum preconsolidation stress give reasonably similar values, although the $P_{i} *^{\prime}$ data tend to plot at slightly higher stresses than the $P_{i}^{\prime}$ values (Fig. 9A). When $P_{i}^{\prime}$ and $P_{i} *^{\prime}$ are plotted against depth (Fig. 9A), most estimated values plot below $P_{o}^{\prime}$, the expected effective lithostatic stress under hydrostatic conditions. Given the potential variation between in situ and laboratory stress conditions, the difference is not considered to be very significant for samples above $\sim 60$ $70 \mathrm{mbsf}$. The discrepancy between $P_{o}^{\prime}$ and the values of both $P_{i}^{\prime}$ and $P_{i} *^{\prime}$, however, increases substantially for samples from below $\sim 60$ 70 mbsf. These data indicate apparent significant underconsolidation and overpressuring in the deeper mélange zone.

A conservative estimate of the range of possible $P_{\text {fexcess }}$ is shown in Figure 9B; the lower and upper $P_{\text {f(excess })}$ limits correspond to the $P_{i}^{\prime}$ and $P_{i} *^{\prime}$ max. data (Fig. 9A) which bracket the bulk of the consolidation estimates. Lambda star $\left(\lambda^{*}\right)$ can be used to represent the degree of in situ overpressuring in sediments and is given by $\lambda *=\left(P_{f(\text { excess })}\right) /$ $\left(P_{o}\right)$. Low in situ effective stresses at near lithostatic pore fluid pressure conditions correspond to $\lambda^{*}$ values that approach 1.0. The data suggest that the fluid pressures are close to hydrostatic above $\sim 70$ mbsf and rise to $\lambda^{*}=\sim 0.8$ by the base of the hole (Fig. 9B). The top of this overpressured zone corresponds to a hydrogeologically active fault that is associated with a well developed temperature spike at $\sim 67 \mathrm{mbsf}$ (see Davis et al. this volume). For comparison purposes, the in situ excess formation pore pressure estimates of 0.25 to $0.3 \mathrm{MPa}$ for the screened interval between 93 and $116 \mathrm{mbsf}$ are also plotted on Figure 9B (Screaton et al., this volume). The in situ and laboratory derived estimates of excess fluid pressure are surprisingly consistent given the potential errors inherent in both methods of determination.

\section{Variations in Volumetric and Hydraulic Conductivity Behavior With Depth and Effective Stress}

Clear differences exist between the volumetric response and hydraulic conductivity behavior of the hanging wall and fault zone samples with varying effective stress. The fault zone samples show a volumetrically stiffer response to varying effective stress, having lower slopes on the $e$ vs. $\log \sigma_{i}{ }^{\prime}$ plots than the hanging wall samples 
Table 1. Summary of consolidation and permeability data.

\begin{tabular}{|c|c|c|c|c|c|c|c|c|c|c|c|c|c|c|c|}
\hline $\begin{array}{l}\text { Sample } \\
\text { I.D. }\end{array}$ & $\begin{array}{c}\text { Hole, core, } \\
\text { section, interval }(\mathrm{cm})\end{array}$ & $\begin{array}{l}\text { Depth } \\
\text { (mbsf) }\end{array}$ & $\begin{array}{l}P_{o}^{\prime} \\
(\mathrm{kPa})\end{array}$ & $\begin{array}{c}K \\
\text { at } P_{o} \\
(\mathrm{~cm} / \mathrm{s})\end{array}$ & $\begin{array}{c}P_{i} \\
\min \\
(\mathrm{kPa})\end{array}$ & $\begin{array}{c}P_{i}^{\prime} \\
(\mathrm{kPa})\end{array}$ & $\begin{array}{c}P_{i} \\
\max \\
(\mathrm{kPa})\end{array}$ & $\begin{array}{c}P_{i^{*}} \\
\min \\
(\mathrm{kPa})\end{array}$ & $\begin{array}{l}P_{i i^{\prime}} \\
(\mathrm{kPa})\end{array}$ & $\begin{array}{c}P_{i^{*}}^{\prime} \\
\max \\
(\mathrm{kPa})\end{array}$ & $\begin{array}{c}P_{\text {flexcess })} \\
\max \\
(\mathrm{kPa})\end{array}$ & $\begin{array}{c}P_{\text {ffexcess })} \\
\text { min } \\
(\mathrm{kPa})\end{array}$ & $\begin{array}{c}K \text { at } \\
P_{i}^{\prime} \\
(\mathrm{cm} / \mathrm{s})\end{array}$ & $\begin{array}{c}K \text { at } P_{i}= \\
\max \\
(\mathrm{cm} / \mathrm{s})\end{array}$ & $\begin{array}{c}K \text { at } \\
\sim 50 \mathrm{kPa} \\
(\mathrm{cm} / \mathrm{s})\end{array}$ \\
\hline $5-1$ & 892D-5X-1, 70-72 & 37.70 & 223 & $2.8 \mathrm{e}-08$ & 42 & 114 & 251 & 70 & 106 & 251 & 110 & -28 & $4.0 \mathrm{e}-08$ & $3.7 \mathrm{e}-08$ & $6.4 e-08$ \\
\hline $7-3$ & $892 \mathrm{~A}-7 \mathrm{X}-3,70-72$ & 52.20 & 322 & $3.4 \mathrm{e}-08$ & & & & & & & & & & & \\
\hline $7-4$ & $892 \mathrm{D}-7 \mathrm{X}-4,64-66$ & 58.86 & 370 & $8.6 e-09$ & 187 & 240 & 340 & 180 & 335 & 440 & 130 & -70 & $1.0 \mathrm{e}-08$ & $6.8 \mathrm{e}-09$ & $2.8 \mathrm{e}-08$ \\
\hline $8-4$ & $892 \mathrm{~A}-8 \mathrm{X}-4,45-47$ & 62.95 & 399 & $2.5 \mathrm{e}-09$ & & & & 129 & 373 & 540 & & -150 & & $1.8 \mathrm{e}-09$ & $4.2 \mathrm{e}-09$ \\
\hline $9-1$ & $892 \mathrm{D}-9 \mathrm{X}-1,50-52$ & 69.82 & 450 & $1.6 \mathrm{e}-09$ & 106 & 211 & 340 & 127 & 217 & 340 & 239 & 110 & $3.2 \mathrm{e}-09$ & $2.2 \mathrm{e}-09$ & $7.3 e-09$ \\
\hline $11-1$ & $892 \mathrm{~A}-11 \mathrm{X}-1,120-122$ & 79.20 & 520 & $8.4 \mathrm{e}-09$ & & & & 311 & 442 & & 78 & & $1.8 \mathrm{e}-08$ & & \\
\hline $10-5$ & $892 \mathrm{D}-10 \mathrm{X}-5,22-24$ & 105.30 & 727 & $4.9 \mathrm{e}-10$ & & & & & & & & & & & \\
\hline $10-8$ & $892 D-10 X-8.25-27$ & 109.60 & 763 & $3.0 \mathrm{e}-09$ & 87 & 152 & 207 & 120 & 212 & 248 & 655 & 516 & $1.45 \mathrm{e}-07$ & $6.0 \mathrm{e}-08$ & $6.5 e-07$ \\
\hline $15-1$ & $892 \mathrm{~A}-15 \mathrm{X}-1,50-52$ & 116.50 & 821. & $1.0 \mathrm{e}-08$ & & & & 144 & 185 & 218 & & 604 & & $1.8 \mathrm{e}-07$ & $4.0 e-07$ \\
\hline $18-1$ & $892 \mathrm{~A}-18 \mathrm{X}-1,33-35$ & 144.00 & 1064 & $1.7 e-09$ & 35 & 95 & 151 & 70 & 220 & 260 & 969 & 804 & $3,47 e-06$ & $5.9 \mathrm{e}-07$ & $5.2 \mathrm{e}-06$ \\
\hline $16-4$ & $892 \mathrm{D}-16 \mathrm{X}-4,126-128$ & 162.30 & 1235 & $8.8 \mathrm{e}-09$ & & & & & & & & & & & \\
\hline $20-2$ & $892 \mathrm{~A}-20 \mathrm{X}-2,126-128$ & 165.40 & 1265 & $1.08 \mathrm{e}-08$ & 65 & 152 & 248 & 92 & 120 & 167 & 1112 & 1098 & $1.9 \mathrm{e}-06$ & $1.1 \mathrm{e}-07$ & $9.0 \mathrm{e}-06$ \\
\hline
\end{tabular}

Notes: $P_{o}^{\prime}=$ effective overburden stress under hydrostatic conditions, $P_{i}^{\prime}=$ maximum preconsolidation stress obtained using volumetric data from the isotropic consolidation stress path, $P_{i^{*}}{ }^{\prime}=$ maximum preconsolidation stress obtained using hydraulic conductivity data, $\mathrm{K}=$ hydraulic conductivity, $P_{f(e x c e s s)}=P_{o}^{\prime}-P_{i^{*}}{ }^{\prime}$ max. The method for evaluating the maximum and minimum range in values is discussed in text.

in both the elastic and plastic portions of the consolidation paths. The spatial variation in the "stiffness" of the samples is shown graphically in Figure 10A, on which the slopes $(a)$ of the plastic and elastic swell curves are plotted separately against depth (where $e=\alpha \log \sigma_{i}^{\prime}+$ constant). It can be seen that the higher $a$ values, corresponding to a volumetrically stiffer response, occur in the samples obtained from below $\sim 70$ mbsf. The $\alpha$ values are also relatively uniform in these deeper samples. Note that the $\sim 70$ mbsf physical property boundary level is close to the subtle change in lithostratigraphy and correlates well with the zone of enhanced cementation, the sharp $\sim 10 \%$ decrease in the water content, and the general downward increase in disruption of the silty clays and clayey silts. It also lies close to the BSR level at $\sim 73 \mathrm{mbsf}$ and the upper active fluid flow conduit at $\sim 68 \mathrm{mbsf}$.

The hydraulic conductivity is plotted against depth on Figure 9C. The boundary limits of the $K$ values correspond to stress levels at $P_{i}^{\prime}$ and the upper boundary of the various preconsolidation stress estimates, $P_{i} *^{\prime} \max$. A clear minimum in $K$ occurs at $\sim 70 \mathrm{mbsf}$, with the hydraulic conductivity increasing by two to three orders of magnitude downwards into the fault zone. This $K$ minimum is also centered on the major $\sim 70$ mbsf physical property discontinuity and zone of enhanced cementation.

A summary of the $e$ vs. $\log K$ relationships are shown in Figure 11. Note that for the most part, the data plot along well developed linear trends and that the fault zone samples (from below $~ 70 \mathrm{mbsf}$ ) characteristically have steeper slopes than the hanging wall samples. Prior to the imposition of significant effective loads, some of the fractured muds in the fault zone below $\sim 70-100$ mbsf also have $K$ values that are two to three orders of magnitude higher than the values of the hanging wall samples. The $K$ values of the fault zone samples, however, rapidly decrease during loading until they are similar to or below the hanging wall samples. This difference in behavior is very clear when the slopes ( $\beta$ ) of the $e$ vs. $\log K$ curves (from Fig. 11) for individual samples (where $e=\beta \log K+$ constant) are plotted against depth. The main change in the $\beta$ values occurs between $\sim 70-100$ mbsf (Fig. 10B) corresponding to the observation of onset of intense deformation, fracturing, and mélange formation in the cores in the deeper section. The slope $(\gamma)$ of the $\log K$ vs. $\log \sigma_{i}^{\prime}$ curves also changes to generally more negative values in the intensely deformed mélanges below a depth of $\sim 110 \mathrm{mbsf}$ (Fig. 10C). The $K$ values of fault zone samples 10-8 and 18-1 thus decrease by 3 to 4 orders magnitude during loading, while the $K$ values of hanging wall samples 5-1 and $7-4$ decrease by less than one order of magnitude.

\section{DISCUSSION}

The fault zone and hanging wall samples behave differently, and this difference will control how the fault zone responds to variations in the hydrogeologic system. The stiffness of the fractured fault zone materials below $\sim 70$ mbsf may be a product of enhanced carbonate/ clay cementation. In a qualitative sense, the fault zone samples certainly appeared to be more indurated and carbonate vein material was observed during sample preparation. The large variations in $K$ of the fault zone materials with little volumetric change is attributed to the presence of initially open microfractures in the highly deformed samples. Direct evidence for the closure of some microfractures can be observed for samples 9-1, 16-4, 18-1, and 20-2 (Figs. 6A, 7A, 7B, and $8 \mathrm{~A}$ ), with significant departures in the $e$ vs. $\log K$ relationships at low effective stresses. These departures generally take the form of sharp anomalous decreases in $K$ with increasing effective confining stress. For samples 9-1 and 16-4 the anomalous changes in slope occur at 48 to $56 \mathrm{kPa}$ respectively. In contrast, samples $18-1$ and 20-2 show anomalous decreases in $K$, corresponding to fracture closure stresses, at $\sim 260 \mathrm{kPa}$ and $\sim 120 \mathrm{kPa}$ respectively. Large volumetric discordances were not, however, observed in the void ratio data at the corresponding stress levels. If the microfractures have an initially high degree of interconnectivity, their eventual closure during consolidation can have a significant effect on $K$ without changing the volume of the sample very much. This is because, by simple analogy with the parallel plate fracture model (Snow, 1968; Snow, 1969), the hydraulic conductivity of the fractures are roughly proportional to the fracture aperture raised to the third power, while the volume of the fracture is only linearly related to the fracture aperture.

It is clear from the narrow temperature anomalies (Davis et al., this volume; Shipboard Scientific Party, 1994) that fluid migration along this fault zone is focused via conduits that are probably associated with open in situ fractures (see also the in situ pump test results in Screaton et al., this volume). The strong contrasts between the $K$ minimum of $=\sim 2 \times 10^{-9} \mathrm{cms}^{-1}$ at $\sim 70 \mathrm{mbsf}$ (associated with enhanced cementation at this level?) and the higher fault zone values of $8 \times$ $10^{-7}$ to $8 \times 10^{-6} \mathrm{cms}^{-1}$ would certainly assist in channeling fluids along this structure. Note, because of scale effects (i.e., the experimental samples are small) it is likely that larger fractures with higher $K$ values may exist in situ. Although it is not certain that microfractures in the laboratory samples were originally open under in situ conditions, a comparison of the fracture closure stress with the $P_{i}^{\prime}$ and $P_{i} *^{\prime}$ values can be used to assess the likelihood of the primary nature of these fractures. For example, the fracture in sample 16-4 is probably a product of sampling disturbance and decompression because this samples $P_{i}^{\prime}$ and $P_{i} *^{\prime}$ values are higher than the $56 \mathrm{kPa}$ level at which the fracture closes/opens. In contrast, the 120 to $260 \mathrm{kPa}$ fracture closure stress observed in samples 18-1 and 20-2 are similar to, or lie above, the samples $P_{i}^{\prime}$ and $P_{i} *^{\prime}$ values. These fractures would have probably been open under in situ stress conditions. From the pump test data, Screaton et al. (this volume) determined that the likely in situ fracture closure stress for the portion of the fault zone lying between 93 and 116 mbsf corresponds to effective confining stresses of $\sim 315 \mathrm{kPa}$. Given the very different scales of observation and dif- 

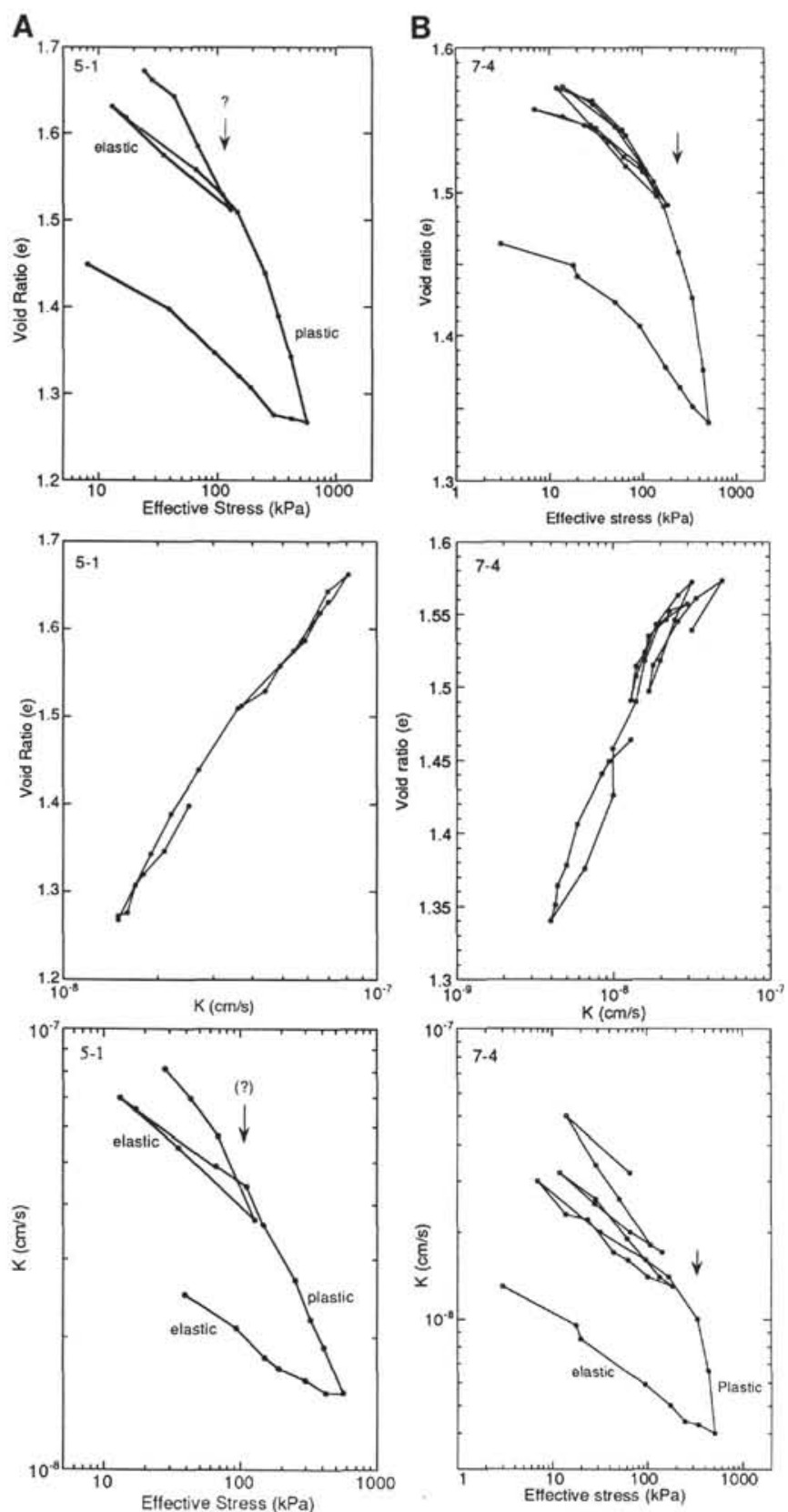

Figure 5. Volumetric and hydraulic conductivity data for (A) Sample 5-1 and (B) Sample 7-4. Arrows denote estimated values for $P_{i} *^{\prime}$ and $P_{i}^{\prime}$ (see Table 1 for ODP sample codes).

ference in applied stress, the in situ fracture closure stress values of $\sim 315 \mathrm{kPa}$ correspond quite closely to the $120-260 \mathrm{kPa}$ range observed in these laboratory tests.

While the anomalous sharp decreases in $K$ in sample 18-1 and sample 20-2 probably relate to the closure of single, relatively large fractures, it is proposed that the anomalous large range in $K$ values, without a correspondingly large change in void ratio for the fault zone materials (Fig. 11), could relate to the progressive closure of numerous smaller fractures. These microfracture networks may have a moderate degree of interconnectivity but contribute only a small amount to the total void volume of the sample. The currently preferred working hypothesis is that the $P_{i}^{\prime}$ and $P_{i} *^{\prime}$ data can also be explained by the nature of the closure mechanisms associated with rough-walled microfractures that preferentially contain local cements
A
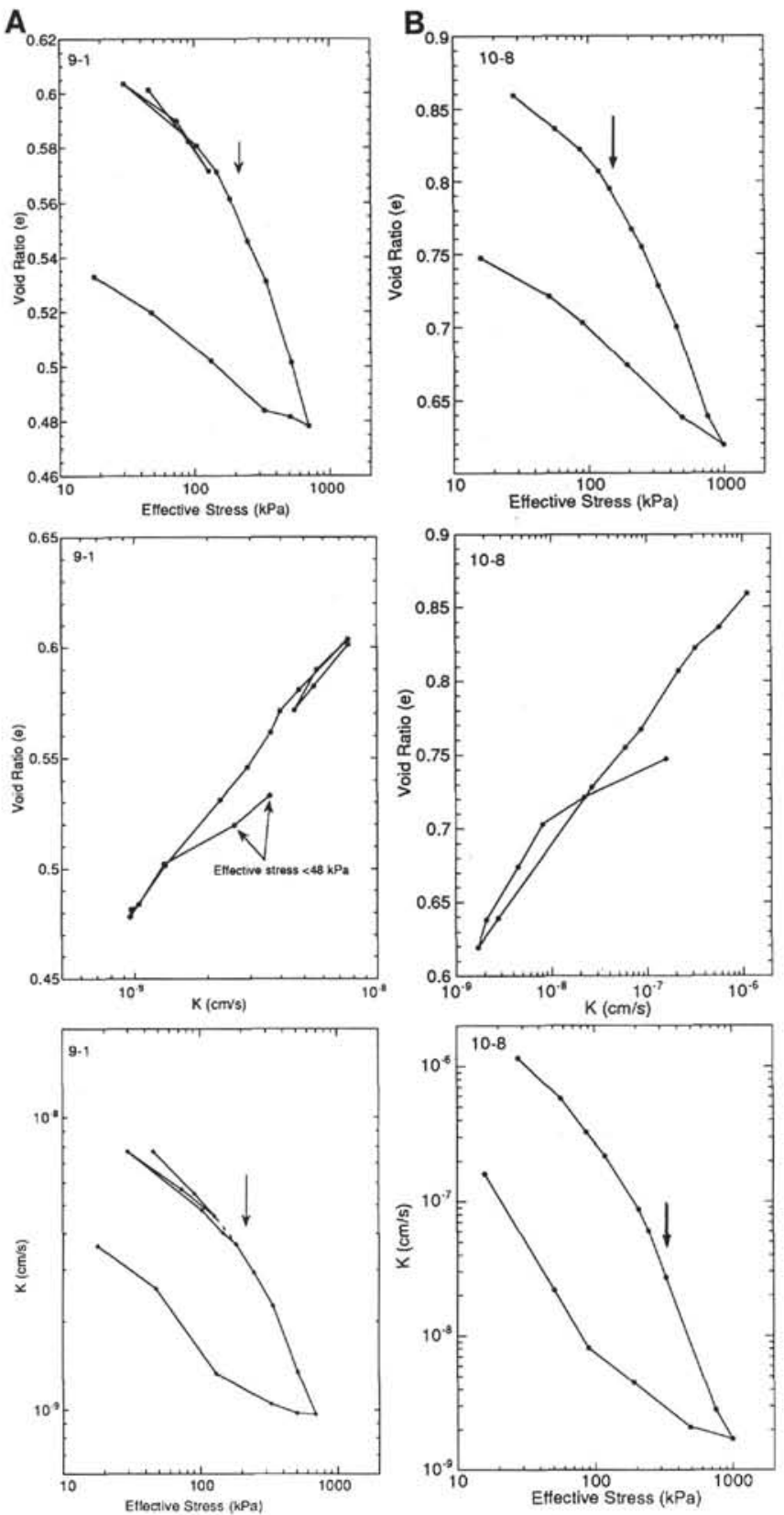

Figure 6. Volumetric and hydraulic conductivity data for (A) Sample 9-1 and (B) Sample 10-8. Arrows denote estimated values for $P_{i} *^{\prime}$ and $P_{i}^{\prime}$ (see Table 1 for ODP sample codes).

and strain hardened sediments (this aspect is still being investigated). Initially, the fractures close elastically (Brown and Scholz, 1986), with the measured $P_{i}^{\prime}$ and $P_{i} *^{\prime}$ values corresponding to the onset of yielding associated with the plastic deformation of lightly indurated/ cemented asperities that hold the microfractures open. The closure of individual larger fractures, with an associated abrupt decreases in $K$, is superimposed on this general behavior.

Whatever the mechanism proposed to account for the large hydraulic conductivity variation of the fault zone samples, they are certainly highly responsive to effective stress/fluid pressure changes. The strong coupling between effective confining stress and $K$ is illustrated in Figure 12, where the $K$ values are plotted against depth for $\lambda^{*}=\sim 0.9\left(\sigma_{i}^{\prime}=50 \mathrm{kPa}\right), \lambda^{*}=0.0\left(\sigma_{i}^{\prime}=P_{o}\right)$, and for stress levels corresponding to $P_{i} *^{\prime} \max$. For $\lambda{ }^{*}$ values close to 1.0 the hydraulic con- 
A
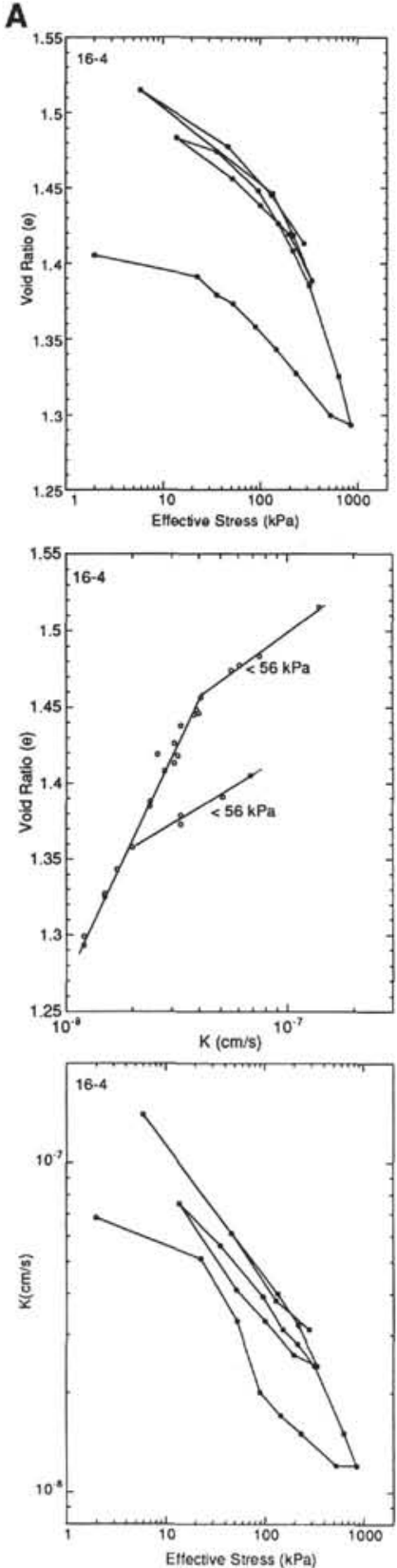
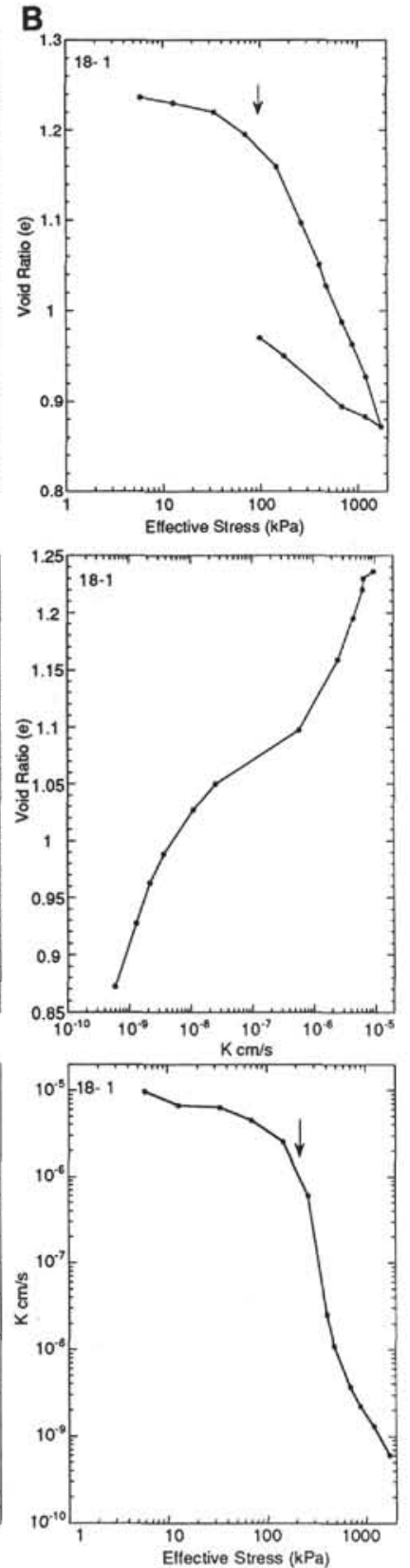

Figure 7. Volumetric and hydraulic conductivity data for (A) Sample 16-4 and (B) Sample 18-1. Arrows denote estimated values for $P_{i} *^{\prime}$ and $P_{i}^{\prime}$ (see Table 1 for ODP sample codes).

ductivity of the fault zone, samples below $80-100$ mbsf are several orders of magnitude higher than the less deformed hanging wall sequences (Fig. 12). As $\lambda *$ decreases towards zero (i.e., effective stresses increase) the hydraulic conductivity of the fault zone samples rapidly decreases by two to three orders of magnitude, until very little difference in hydraulic conductivity exists between the hanging wall and fault zone. In contrast, the $K$ values for hanging wall samples change very little. The general changes in the hydraulic conductivity profile depicted in Figure 12 are consistent with the data obtained from the in situ packer and pump tests (Screaton et al., this volume). The in situ data indicate that the average hydraulic conductivities of the fractured section between 93 to 116 mbsf varies by two to three orders of magnitude as $\lambda^{*}$ varies between $\sim 0.0$ and $\sim 1.0$. This type
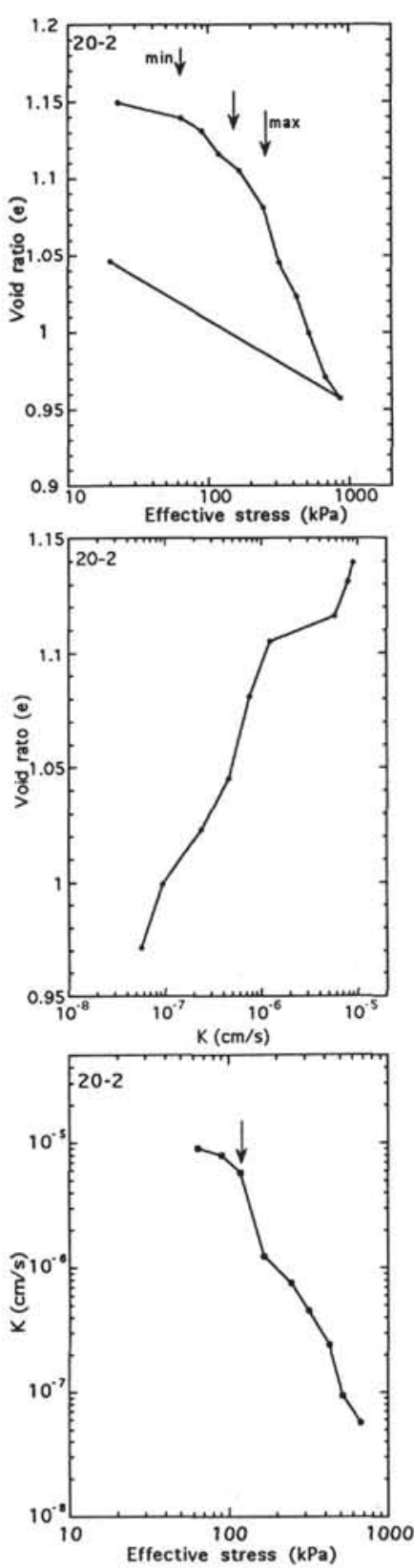

Figure 8. Volumetric and hydraulic conductivity data for Sample 20-2. Arrows denote estimated values for $P_{i} *^{\prime}$ and $P_{i}^{\prime}$ (see Table 1 for ODP sample codes).

of behavior creates a highly non-linear system with the existence of the hydraulic conductivity sufficient for continued fluid flow along this structure being strongly coupled to the maintenance of high pore fluid pressures within it.

\section{CONCLUSIONS}

Reported herein are the results of a series of laboratory tests conducted on discrete samples of clayey silts and silty clays that are the dominant lithologies in both the hanging wall and the thrust zone penetrated at Site 892. Mélanges are well developed within the fault between 100 to $160 \mathrm{mbsf}$ but several hydrogeologically active strands of the thrust are intersected over a zone that ranges from $\sim 67$ 
Figure 9. A. Estimates of the maximum preconsolidation stress (also see Table 1). $P_{o}^{\prime}$ is the effective lithostatic stress under hydrostatically pressured conditions. $P_{i}^{\prime}$ is the maximum past consolidation stress estimate obtained from the $e$ vs. $\log \sigma_{i}{ }^{\prime}$ plots. $P_{i} *^{\prime}$ is the maximum past consolidation stress estimate obtained from the $\log K \mathrm{vs} . \log \sigma_{i}^{\prime}$ plots. The respective max. and min. values correspond to the potential error in the $P_{i}^{\prime}$ and $P_{i} *^{\prime}$ estimates. Because of the effects of sample disturbance, a conservative estimate of the maximum preconsolidation pressure is likely to fall closer to the maximum range of values than the minimum values. B. The excess fluid pressure above hydrostatic $\left(P_{\text {fiexcess }}\right)$ is shown plotted against $\lambda *$. The maximum and minimum $P_{\text {f(excess })}$ curves correspond to $P_{o}^{\prime}-P_{i}^{\prime}$ and $P_{o}^{\prime}-P_{i} *^{\prime}(\max )$ respectively. C. Hydraulic conductivity $(K)$ vs. depth. Hydraulic conductivities are shown at stresses corresponding to $P_{i}^{\prime}$ and $P_{i} *^{\prime}(\max )$.

Figure 10. The $\alpha, \beta$, and $\gamma$ slopes respectively of the (A) $e$ vs. $\log \sigma_{i}^{\prime}$, (B) $\log K$ vs. $e$, and (C) $\log K$ vs. $\log \sigma_{i}{ }^{\prime}$ curves. Note the changes in these parameters between the hanging wall (above $\sim 70 \mathrm{mbsf}$ ) and fault zone region (below 70-100 mbsf).
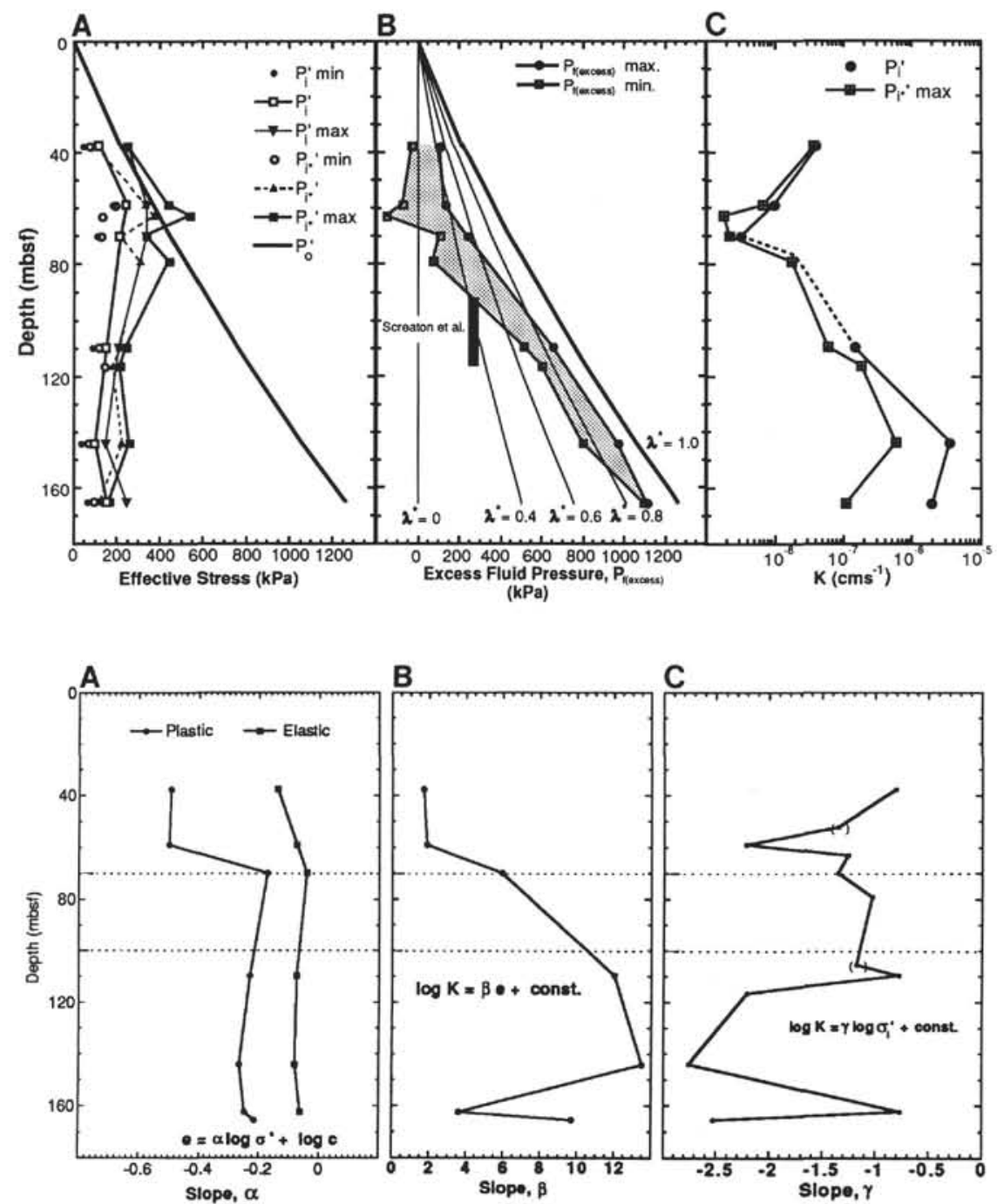

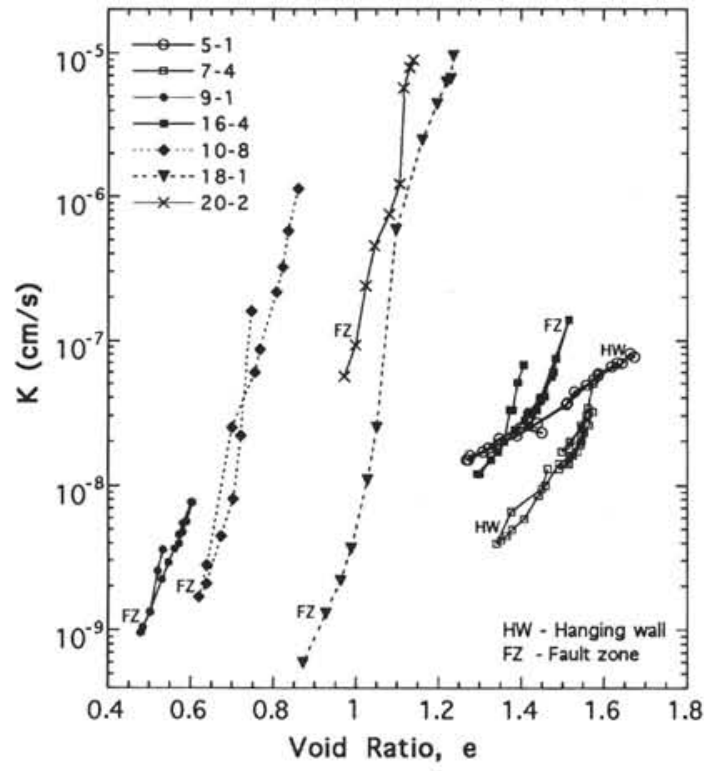

Figure 11. Summary of the $\log K$ vs. $e$ relationships. Note the differences in slope between the hanging wall and fault zone samples.

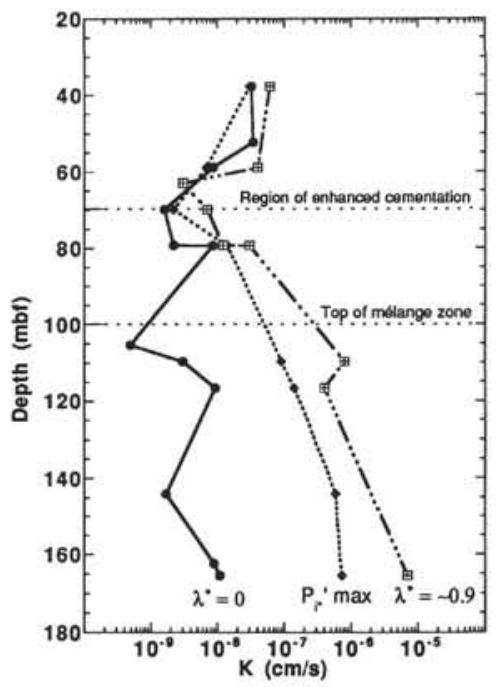

Figure 12. The variation of $K$ with depth and degree of overpressuring. Note the strong coupling of the fault zone $K$ response to changes in fluid pressure. 
to $\sim 125 \mathrm{mbsf}$. It was found that, although the fault zone samples have generally low water contents and a volumetrically stiff response, the stress values at the onset of yielding and plastic deformation rarely rise above $\sim 225 \mathrm{kPa}$, for the fractured samples obtained from depths below $\sim 70$ mbsf. This suggests significant underconsolidation and overpressuring within in the fault zone. At stress levels below $\sim 225$ $\mathrm{kPa}$ the fractured fault zone materials have relatively high hydraulic conductivity $(K)$ values of $10^{-5}$ to $10^{-7} \mathrm{cms}^{-1}$. This contrasts with the hanging wall section where $K$ values range between $10^{-7}$ and $10^{-9}$ $\mathrm{cms}^{-1}$. As effective confining stress levels exceed $\sim 225 \mathrm{kPa}$, however, the fault zone samples yield and their $K$ values rapidly drop by several orders of magnitude to levels as low as the hanging wall samples $\left(<10^{-8} \mathrm{cms}^{-1}\right)$. This strong coupling between $K$ and effective confining stress will give rise to a strong non-linearity in the hydrogeologic system associated with this fault zone. The generally sharp decrease in $K$ in the fault zone samples as stresses rise beyond the yield point is accompanied by only a small reduction in void ratio and may be related to the closure of microfractures. The origin of the apparent state of underconsolidation within the fractured fault zone materials is not clear and forms the object of further experimental study. A preliminary interpretation is that the observed low-yield stresses associated with the mélange samples is related to the onset of asperity deformation during the initial phase of closure of numerous rough-walled microfractures originally formed under overpressured conditions.

\section{ACKNOWLEDGMENTS}

The author would like to thank Harold Olsen and John Billam for their helpful and informative reviews, Mike Tryon for his assistance with the figures, and the shipboard scientific party, technicians and crew on Leg 146 for a productive and enjoyable cruise. This work was funded by USSSP No \# 146-20694b.

\section{REFERENCES}

Brown, S.R., and Scholz, C.H., 1986. Closure of rock joints. J. Geophys. Res., 91:4939-4948.

Casagrande, A., 1936. The determination of preconsolidation load and its practical significance. In Casagrande, A., Rutledge, P.C., and Watson, J.D. (Eds.), Proc. 1st Int. Conf. Soil Mech. Found. Eng., Am. Soc. Civ. Eng., 3:60-64.

Freeze, R.A., and Cherry, J.A., 1979. Groundwater: Englewood Cliffs, NJ (Prentice-Hall).

Lambe, T.W., and Whitman, R.V., 1979. Soil Mechanics (SI ver.): New York (Wiley).

Moore, J.C., Jeanbourquin, P., and Sample, J., in press. Thrusting, fluid flow, and chemosynthetic bioherm development: Oregon accretionary prism. Geol. Soc. Am. Bull.

Olsen, H.W., Morin, R.H., and Nichols, R.W., 1988. Flow pump applications in triaxial testing. In Donaghe, R.T., Chaney, R.C., and Silver, M.L. (Eds.), Advanced Triaxial Testing of Soil and Rock. ASTM Spec. Tech. Publ., 977:68-81.

Olsen, H.W., Nichols, R.W., and Rice, T.L., 1985, Low gradient permeability measurements in a triaxial system. Geotechnique, 35:145-157.

Olson, R.E., and Daniel, D.E., 1981. Measurement of the hydraulic conductivity of fine-grained soils. In Zimmie, T.F., and Riggs, C.O. (Eds.), Permeability and Groundwater Contaminant Transport. ASTM Spec. Tech. Publ., 746:18-64.

Pane, V., Croce, P., Znidarcic, D., Ko, H.-Y., Olsen, H.W., and Schiffman, R.L., 1983. Effects of consolidation on permeability measurements for soft clay. Geotechnique, 33:67-72.

Shipboard Scientific Party, 1994. Site 892. In Westbrook, G.K., Carson, B., Musgrave, R.J., et al., Proc. ODP, Init. Repts., 146 (Pt. 1): College Station, TX (Ocean Drilling Program), 301-378.

Snow, D.T., 1968. Rock fracture spacings, openings, and porosities. J. Soil Mech. Found. Div., Am. Soc. Civ. Eng. Proc., 94:73-91. 1969. Anisotropic permeability of fractured media. Water Resour. Res., 5:1273-1289.

Date of initial receipt: 2 September 1994

Date of acceptance: 23 February 1995

Ms 146SR-218 